\title{
Final Report (2008-2011)
}

\section{Project Title:}

\section{Monitoring Uranium Transformations Determined by the Evolution of Biogeochemical Processes: Design of Mixed Batch Reactor and Column Studies at Oak Ridge National Laboratory}

\author{
Craig S. Criddle and Weimin $\mathrm{Wu}$ \\ Department of Civil and Environmental Engineering \\ Stanford University, Stanford, CA 94305-4020
}

\begin{abstract}
With funds provided by the US DOE, Argonne National Laboratory subcontracted the design of batch and column studies to a Stanford University team with field experience at the ORNL IFRC, Oak Ridge, TN. The contribution of the Stanford group ended in 2011 due to budget reduction in ANL. Over the funded research period, the Stanford research team characterized ORNL IFRC groundwater and sediments and set up microcosm reactors and columns at ANL to ensure that experiments were relevant to field conditions at Oak Ridge. The results of microcosm testing demonstrated that $\mathrm{U}(\mathrm{VI})$ in sediments was reduced to $\mathrm{U}(\mathrm{IV})$ with the addition of ethanol. The reduced products were not uraninite but were instead U(IV) complexes associated with Fe. $\mathrm{Fe}(\mathrm{III})$ in solid phase was only partially reduced. The Stanford team communicated with the ANL team members through email and conference calls and face to face at the annual ERSP PI meeting and national meetings.
\end{abstract}

Keyword: uranium, iron, sediments, bioreduction, reoxidation, microcosm, column, synchronal analysis

Over the period of three subcontracts (DE-FG02-07ER64364 for 3/15/07 - 3/14/10; DOE 0F34161 for 6/15/10 - 6/14/11; and DOE 1F-31801 for 4/15/11 - 7/14/12), ANL subcontracted to the Stanford research team work on the design of static microcosm (SM) tests, including monitoring and investigation of biogeochemical changes in relation to the stability and reduction-oxidation of uranium at the molecular scale. In 2010, the relative dynamics of UVI reduction and speciation of UIV in mixed batch reactors and column studies were monitored under Fe- and sulfate-reducing conditions. This research represents the combined efforts of Drs. Shelly Kelly (ANL), M.I. Boyanov (ANL), Edward O’Loughlin (ANL), Ken Kemner (ANL) and other ANL tem members, Drs. Craig Criddle, Wei-Min Wu at Stanford University and Dr. Terry Marsh at Michigan State University. 
Efforts at ANL focused on monitoring the U speciation and aqueous chemical composition (e.g., $\mathrm{pH},[\mathrm{U}(\mathrm{VI})],[\mathrm{Fe}(\mathrm{II})]$, sulfate, etc.) with time in static microcosms. Six microcosms were initiated in July 2008 and have been monitored continuously to study the long-term effect of geochemical changes on uranium speciation in relation to its immobilization and stability. Microcosm sediments and groundwater were surged from Area 3, US DOE IFRC Oak Ridge site. Sediments $(220 \mathrm{ml})$ and groundwater were transferred on under anoxic conditions to $500 \mathrm{ml}$ polycyclic bottles. Two different level of sulfate $(1.0 \mathrm{vs} 5.0 \mathrm{mM})$ were used to test the effect of sulfate on bioreduction. The initial $\mathrm{pH}$ was 7.0 with alkalinity $\sim 4.0 \mathrm{mM}$. The microcosms were stored in an anoxic Coy chamber, except for the 1 to 4 hours required to make X-ray measurements at the MRCAT beamline at the APS. The aqueous phase Fe(II), [U]tot and pH were recorded. The microcosms showed changes consistent with the development of reducing conditions. The $\mathrm{pH}$ of the groundwater increased, aqueous [Fe(II)] decreased and [U]tot fell below detection limits. In the microcosms with initial high sulfate, the $\mathrm{pH}$ gradually rose to above 8.0 and rebound of aqueous U(VI) concentration was observed. Over long-term, all sulfate was removed by microbial reduction and the $\mathrm{pH}$ become stabilized.

The x-ray probe was used to scan of 0.5 by $0.5 \mathrm{~mm}$ of each microcosm from the groundwatersediment interface down vertically for the X-ray Absorption Near Edge Structure (XANES) of uranium valence and Extended X-ray absorption fine structure (EXAFS) for the U chemical speciation. Detailed analysis of these spectra from the first series of microcosms show that $\mathrm{U}(\mathrm{VI})-\mathrm{C}$ and $\mathrm{U}(\mathrm{VI})-\mathrm{P}$ species were transformed to uraninite U(IV).

Dr. Criddle has lent his guidance in the SMs tests and the interpretation of results. Dr. Wu has contributed to the monitoring and maintaining the SMs, sample analysis arrangement and data reduction. Both Drs. Criddle and Wu communicated with ANL SFA team through email and conference call. Dr. Wu meet ANL SFA team at ANL in September, 2010 and 2011, the annual DOE BRE meeting in 2009, 2010 and 2011, and ASM annual meetings in 2009, 2010 and 2011. On these meetings, Stanford team discussed project

\section{Test procedures and results}

\section{Microcosm test with added sulfate and ethanol as electron donor source.}

Six microcosms with the same size were set up to test the effect of amendment with ethanol and impact of sulfate concentrations on U(VI) reduction. Each microcosm contained $580 \mathrm{~mL}$ of sediment slurry taken from Area 3, IFC Oak Ridge site (about $215 \mathrm{~g}$ dry weight per microcosm). Two different initial sulfate concentrations $(1.0 \mathrm{vs} 4.0 \mathrm{mM})$ were used. Ethanol $(10 \mathrm{mM})$ was

added to the four microcosms (two with $1.0 \mathrm{mM}$ sulfate and two with $4.0 \mathrm{mM}$ sulfate). The control microcosms did not receive ethanol (Figure 1). The monitoring procedures of this set of microcosms was the same as that published by Shelly et al. (2010). 
These microcosms were monitored by withdrawing aqueous samples for $\mathrm{pH}$, sulfate, $\mathrm{U}(\mathrm{VI})$, ethanol, acetate, Fe and Ca periodically. The XANES and EXAFS were used to determine the valence and $\mathrm{U}$ chemical speciation as described about.

The results indicated that significant $\mathrm{U}(\mathrm{VI})$ removal in aqueous phase and sulfate reduction occurred when ethanol was added. Slow removal of U(VI) and sulfate was observed in the control. Slightly more U(IV) content was observed in the microcosms with added higher sulfate concentration. The sediments in the microcosms were reduced from upper to lower portion over a long-term period (Figure 2).

The change in aqueous geochemistry of each microcosms is illustrated in Figure 3. Ethanol was consumed rapidly and acetate produced was then consumed. Sulfate was gradually reduced, resulting in increase in $\mathrm{pH}$. U concentration declined after amendment except for that contained high sulfate. In that case, $\mathrm{U}$ was increased due to $\mathrm{pH}$ raising and finally decreased as $\mathrm{pH}$ become stable or sulfate was consumed.

\section{Microbial analysis}

Sediments have been archived for microbial analysis in progress. Samples were collected from the initial $\mathrm{U}(\mathrm{VI})$ microcosms inoculum and with depth from the microcosms.

Clone libraries of $16 \mathrm{~S}$ sequences were used to study the shifts of microbial communities. The twelve samples were i.) the initial FRC sediment (ECFW026), ii.) an aliquot of the initial sediment stored in $4^{\circ} \mathrm{C}$ in which uranium reduction was observed (May0308_FW026Pulled12706), iii.) Microcosm (Microcosm 1 vs. Microcosm 2) samples taken eleven months apart (May 3rd, 2007 vs. April 21st, 2008) at two different positions for aqueous and sludge samples (top vs. bottom), and iv.) the inocula for Microcosm 10 (high $\mathrm{SO}_{4}{ }^{2-}$ vs. low $\mathrm{SO}_{4}{ }^{2-}$ ). Clone libraries of at least 138 sequences per sample were constructed with the totoal of 1888 cloned 16S rRNA genes. The resulting 16S sequences were analyzed for ecological parameters using distance matrix with DOTUR (DOTUR 1.53), the Ribosomal Database Project (RDP) Classifier, and neighbor joining implemented in ARB.

Ecological parameters. Individual samples were analyzed with Dotur 1.53 to generate diversity indices and estimates of operational taxonomy units (OTU) . Shannon and Simpson diversity indices were consistent with each other (Table 1.), ranging from 2.73-3.75 and 0.03-0.14 respectively. We also report values for Chao- 1 and ACE as estimates of the number of species in these samples. These indices suggested that the Microcosm 10 inocula (May2008_Micro10LowSO4 and May2008_Micro10HighSO4) and the FRC sediment aliquot stored in $4^{\circ} \mathrm{C}$ (May0307_FW026Pulled12706) were less diverse compared to the remaining 
samples. Analysis of the initial FRC sediment (ECFW026) revealed a complex community that was used as the inoculum for Microcosm 1 and 2. The communities of the 'early' microcosm enrichments (May0307_Micro1Top and Bottom, May0307_Micro2Top and Bottom) appeared less even and less diverse compared to the starting inoculum. Eleven months later, an increasingly diverse and complex community that approached the complexity of the original FRC sediment community was detected (Apr2108_Micro1Top and Bottom, Apr2108_Micro2Top and Bottom). Thus, the detectable diversity of the U(VI) microcosm communities experienced an initial decrease in richness and diversity, presumably as a result of strong selection, followed by increases in richness and diversity as the original selection pressures diminished. As reported above by ANL, U(VI) reduction was observed in Microcosm 1 and 2 during the same eleven month period. Thus, the detectable diversity might be directly associated to the concentration of U(VI). Variations in richness and evenness were also observed amongst aqueous and sludge samples taken during the same period of time. However, no interpretable patterns in diversity indices could be detected between aqueous (Top) and sludge (Bottom).

Table 1. Diversity indices of microcosm communities.

\begin{tabular}{lllllll}
\hline & \multicolumn{2}{c}{ Indices } & & & & \\
OTUs & \multicolumn{2}{c}{$\begin{array}{c}\text { No. of } \\
\text { Clones }\end{array}$} \\
\cline { 2 - 6 } & Ace & I & Shannon & Simpson & & \\
\hline \hline May2008_Micro10LowSO4 & 109.07 & 74.14 & 2.73 & 0.11 & 38 & 163 \\
May2008_Micro10HighSO4 & 76.76 & 55.83 & 2.83 & 0.12 & 40 & 149 \\
\hline May0307_FW026Pulled12706 & 79.95 & 76.50 & 2.75 & 0.14 & 38 & 139 \\
\hline ECFW026 & 166.55 & 159.66 & 3.74 & 0.03 & 64 & 138 \\
May0307_Micro2Bottom & 126.22 & 134.67 & 3.12 & 0.09 & 52 & 175 \\
May0307_Micro1Top & 86.63 & 74.60 & 3.26 & 0.06 & 47 & 156 \\
May0307_Micro1Bottom & 118.75 & 105.38 & 3.28 & 0.06 & 51 & 170 \\
May0307_Micro2Top & 118.00 & 106.38 & 3.31 & 0.06 & 52 & 165 \\
Apr2108_Micro2Top & 94.94 & 107.50 & 3.35 & 0.05 & 49 & 151 \\
Apr2108_Micro1Top & 177.26 & 161.50 & 3.38 & 0.05 & 59 & 163 \\
Apr2108_Micro1Bottom & 197.87 & 240.50 & 3.71 & 0.03 & 68 & 171 \\
Apr2108_Micro2Bottom & 180.68 & 136.00 & 3.81 & 0.03 & 70 & 148 \\
\hline
\end{tabular}

*Values were calculated at 97\% similarity via DOTUR-1.53

Classification. The sample sequences were submitted to the Ribosomal Database Project (RDP) for classification at phylum and genus level (80\% confidence level). All sequences were classified as bacteria (Table 2.). Approximately $4-12 \%$ of clones per sample were identified as unclassified bacteria at phylum level. Three phyla (Proteobacteria, Acidobacteria and 
Chloroflexi) were detected in all samples at variable abundance. Proteobacteria was the predominant group in all twelve samples (30-60\%), especially in the initial FRC sediment. The early U(VI) microcosm samples (May0307_Micro1\&2 samples) revealed a substantial decrease in detectable Proteobacteria population. However, Proteobacteria populations increased in the two microcosms eleven months later (Apr2108_Micro1\&2 samples). Although Acidobacteria was present in all of the samples, the Acidobacteria population detected in Microcosm 10 inocula (May2008_Micro10LowSO4 and May2008_Micro10HighSO4) and FRC sediment aliquot stored at $4^{\circ} \mathrm{C}$ (May0307_FW026Pulled12706) was significantly lower than the remaining nine samples. The Acidobacteria group behaved exactly opposite to the Proteobacteria in that relatively low abundance of Acidobacteria was detected in the initial FRC sediment but appeared to increase in the early sampling of the U(VI) microcosms (May0307_Micro1\&2 samples). The abundance of Acidobacteria in the same microcosms eleven months later was found to decrease and became comparable to the initial FRC sediment (Apr2108_Micro1\&2 samples). The rise and fall of Proteobacteria and Acidobacteria population suggested that these populations were responding to the $\mathrm{U}(\mathrm{VI})$. As remediation continued and $\mathrm{U}(\mathrm{VI})$ was coverted to $\mathrm{U}(\mathrm{IV})$, the community responded and rebounded to a structure that resembled the original inoculum as measured by diversity indices. Besides Proteobacteria and Acidobacteria, phylum Chloroflexi was also reported in all of the samples. The abundance of Chloroflexi was significantly higher in Microcosm 10 inocula than the rest of the samples. The Classifier results suggested that both Micro10 inocula samples has substantial numbers of Firmicutes as well. Interestingly, although Firmicutes were present in low abundance in Microcosm 1 and 2 sludge samples, none were detected in the aqueous portions of microcosms. At genus level, approximately $30-70 \%$ of the sequences could not be identified by the RDP Classifier. Amongst all classifiable microorganisms, genus GP8 (phylum Acidobacteria) and Geobacter were present in all samples. The Classifier data at the phylum level indicated that the detectable abundance of GP8 was significantly lower in May2008_Micro10LowSO4 and May2008_Micro10HighSO4 but higher in the microcosms that were abundant with U(VI). Cluster analysis with the Bray-Curtis similarity index using genus level Classifier results showed that twelve samples could be grouped into three clades, i.) the FRC sediment aliquot stored at $4^{\circ} \mathrm{C}$, ii.) the two Microcosm 10 samples, iii.) the initial FRC sediment and eight Microcosm 1 and 2 samples. The dendrogram revealed that the FRC sediment aliquot stored at $4^{\circ} \mathrm{C}$ was different from the rest of the samples. Hence, temperature was also an important parameter that determined the community structure of these uranium reducing samples.

Phylogenetic Analyses. The sequences were also aligned to the Arb Silva database for more rigorous phylogenetic analyses. To date, all sequences have been aligned and the results are consistent with the classifier outputs. The neighbor joining trees revealed several large groups of previously unidentified bacteria (e.g., within the Chloroflexi group). Further grouping and identification is in progress. In the coming 6-12 months, we will i.) complete the phylogenetic analyses of the $16 \mathrm{~S}$ sequences, ii.) compare the communities via UniFrac and Libshuff, iii.) 
determine microorganisms that are essential for uranium reduction within the communities, iv.) target the dominated uncultured bacteria for isolation and investigate their ability in heavy metal reduction. As our ultimate goal, we will synthesize a community that is capable for rapid uranium reduction with the least complexity.

\section{Publications and Conference presentations contributed by Stanford Team}

The results of this project have been partially published in peer-reviewed journals and presented as posters at several conferences as below.

1. Kelly, S.D., K.M. Kemner, J. Carley, C. Criddle, D. Phillips, P.M. Jardine, T. L. Marsh, D. Watson, W.-M. Wu. 2008. Speciation of uranium in sediments before and after in situ bioreduction. Environmental Science \& Technology. 42: 1558-1564.

2. Kelly, S.D., W.-M. Wu, F. Yang|, C. Criddle, T. L. Marsh, E. J. O’Loughlin, B. Rave, D. Watson, P.M. Jardine, K.M. Kemner 2010. Monitoring uranium transformations in static microcosms. Environmental Science \& Technology. 44(1): 236-242.

3. Kelly, S.D., K. M. Kemner, E. J. O’Loughlin, W.-M. Wu, C. Criddle, T. L. Marsh. 2008. Monitoring uranium transformations. Poster presented at Goldschmidt Conference 2008. Vancouver, Canada. July 13-18, 2008.

4. Boyanov, M., E. O’Loughlin1, K. Skinner-Nemec, M. J. Kwon, S. Kelly, F. Yang, T. Marsh, W.-M. Wu, C. Criddle, K.Kemner. 2009. Combined x-ray, chemical, and biological characterization of biostimulated and sulfate-amended sediments from the Oak Ridge Field Research Center. Poster presented at 2009 AGU Fall Meeting, San Francisco, California, USA. December 14-18.

5. Boyanov, M, E. O’Loughlin, S. Kelly, K. Skinner-Nemec, M.-J. Kwon, W.-M Wu, C. Criddle, T. Marsh, F. Loefler, R. Sanford, C.Giometti, M.Scherrer, K. Kemner. 2009. The interplay between sulfate- and iron-reducing conditions: effect on uranium speciation studied in static and flow-through columns. Poster presented at 4th DOE-ERSP PI Meeting, Lansdowne, VA, April 20-23, 2009.

6. O’Loughlin, E., M. Boyanov, E. Carpenter, C.Criddle, J. Fredrickson, C. Giometti, P. Jardine, M. Kwon, L. Liang, T. Marsh, M. Mccormick, R. Sanford, M. Scherer, D. Sholto-Douglas, K. Skinner-Nemec, W. Wu, K. Kemner. 2009. The Argonne subsurface science program scientific focus area. Poster presented at 4th DOE-ERSP PI Meeting, Lansdowne, VA, April 20-23, 2009.

7. Boyanov, M , E.J. O’Loughlin, M.J.Kwon, K. Skinner, B. Mishra, C. Criddle, W.-M. Wu, F. Yang, T. Marsh, K.E. Fletcher, F.E. Löeffler, K.M. Kemner. 2010. The Influence of ligands on the formation of non-uuaninite U(IV) phases during biotic and abiotic U(VI) Reduction. Poster presented at 5th DOE-ERSP PI Meeting, Washington, D.C., March 29-31, 2010.

8. Kemner, K., E. O’Loughlin, M. Boyanov, D. Antonopoulos, S. Brooks, E. Carpenter, C. Criddle, J.Fredrickson, T.Henne, M.-J. Kwon, B.Lai, D. Latta, F. Loeffler, T. Marsh, M. McCormick, B.Mishra, R.Sanford, C. Segre, M. Scherer, D. Sholto-Douglas, K. Skinner, W.-M. Wu, C. Giometti. 2011. The Argonne Subsurface Science Program scientific focus area. Poster presented at The Department of Energy's SBR $6^{\text {th }}$ Annual PI Meeting, Washington, D.C., April 26 - 28, 2011. 
9. Boyanov, M.I., E. J. O'Loughlin, K. Skinner-Nemec, S.D. Kelly, W.-M. Wu, C.Criddle, F. Yang, T. March, Mueller, T. Melhorn, K. Lowe, D. Watson, S.Brooks, K. M. Kemner. 2011. Non-uraninite U(IV) phases in biostimulated sediments from the Oak Ridge IFRC. Poster presented at The Department of Energy's SBR $6^{\text {th }}$ Annual PI Meeting, Washington, D.C., April 26-28, 2011.

10. Wu, W.-M., C.S. Criddle, D.Watson, S. Brooks, C. Schadt, T. Gihring, G. Zhang, T.Mehlhorn, K. Lowe, J. Phillips, J. Earles, C. Brandt, P. Jardine, K.Kemner, M. Boyanov, J. E. Kostka, W. Overholt, S. J. Green, P. Zhang, J. Von Nostrand, J. Zhou. 2011. Biological reduction of uranium in the contaminated subsurface by slow-release electron donor. Poster presented at The Department of Energy's SBR $6^{\text {th }}$ Annual PI Meeting, Washington, D.C., April 26 - April 28, 2011.

11. Wu, W.-M., D. Watson, G. Zhang, T. Gihring, C. Schadt, T. Mehlhorn, F. Zhang, S. D. Kelly, M. Boyanov, K. M. Kemner, J. D. Van Nostrand, P. Zhang, J. Zhou, W. A. Overholt, S.J. Green, J. E. Kostka' C. S. Criddle, P. M. Jardine, S. C. Brooks. 2011. U(VI) reduction in contaminated sediments with oleate, emulsified vegetable oil and ethanol as electron donor. Poster presented at American Society for Microbiology $111^{\text {th }}$ General Meeting, New Orleans, LS, May 21-24, 2011
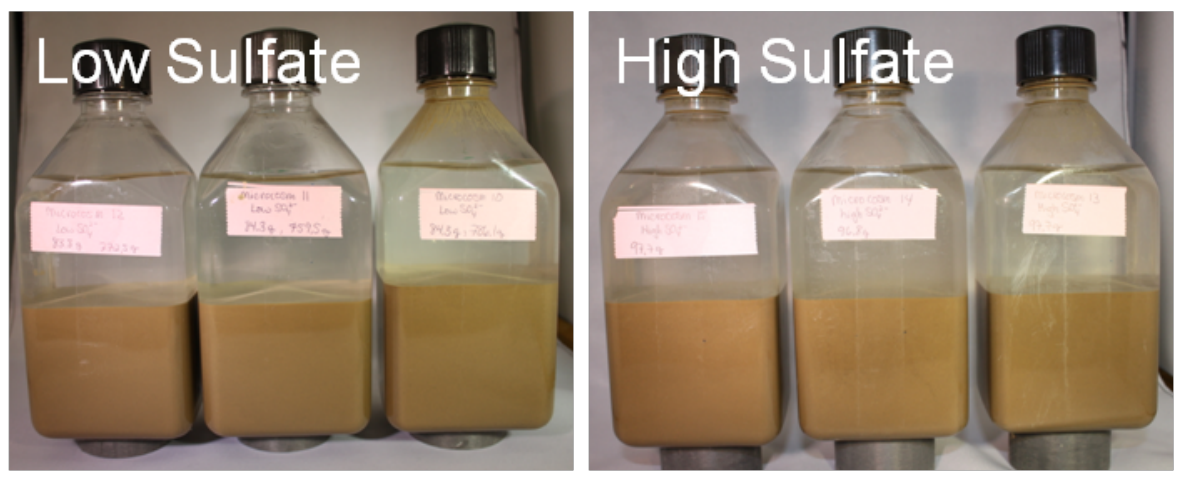

Figure 1. Microcosms prior to adding ethanol for bioreduction. Low sulfate microcosms contained $1 \mathrm{mM}$ and high sulfate was $4 \mathrm{mM}$. 


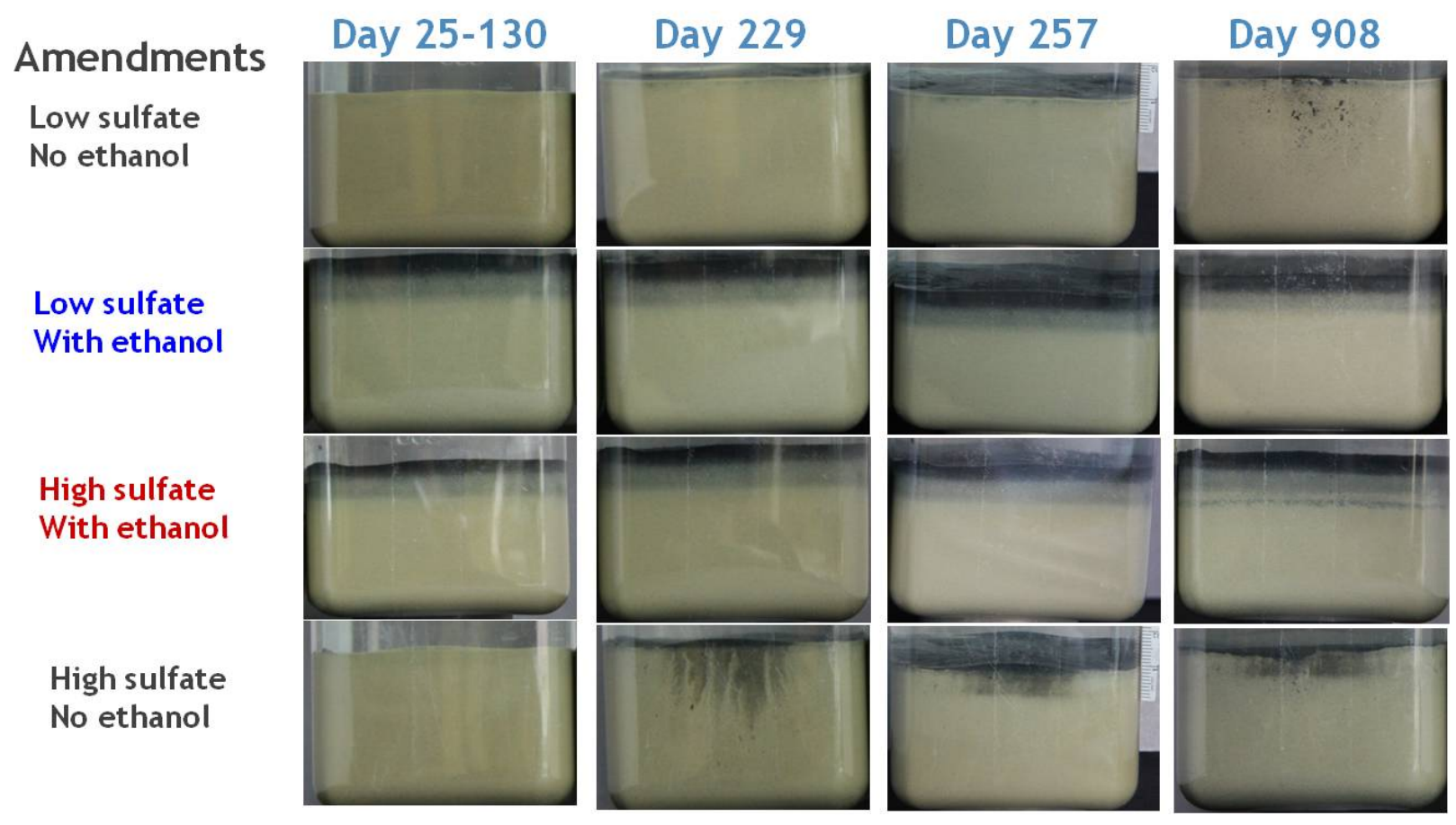

Figure 2. The progress of bioreduction of sediments in microcosms after ethanol amendment.
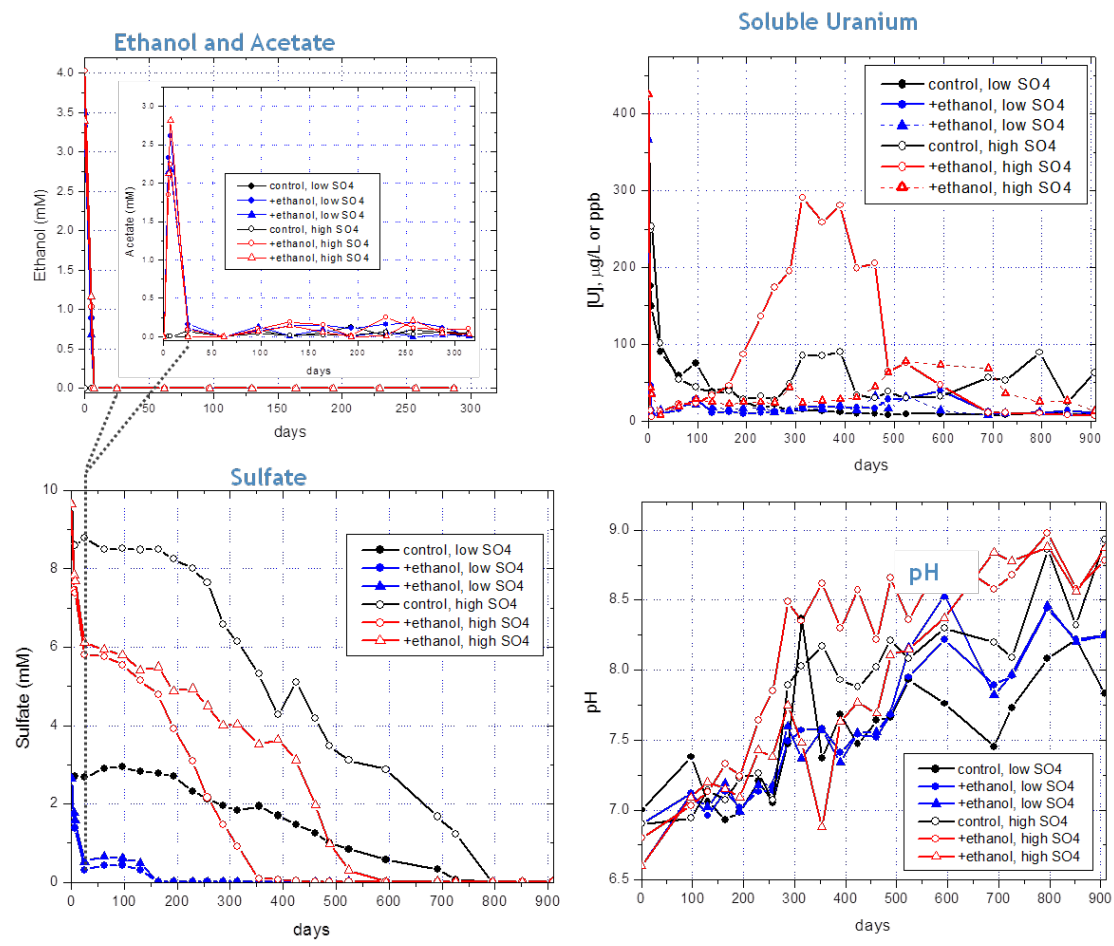
Figure 3. Change in geochemistry during the test (ethanol + acetate, sulfate, uranium and $\mathrm{pH}$ ). 